\title{
LA ORFEBRERÍA PROCEDENTE DE LAS NECRÓPOLIS FENICIAS DE MALACA
}

\section{JEWELRY FROM THE PHOENICIAN NECROPOLISES OF MÁLAGA}

\author{
JUAN ANTONIO MARTÍN RUIZ* \\ SERGIO FERNÁNDEZ RECHE*
}

Resumen: En este artículo se estudian las piezas de oro procedentes de los enterramientos fenicios de Málaga, la mayor parte de las cuales pueden datarse en el siglo VI a. C. Así mismo, se valora la posible existencia en este asentamiento de un taller que, junto a sus lógicas similitudes con otras piezas fenicias del Mediterráneo central y occidental, parece mostrar ciertas peculiaridades formales y decorativas.

Palabras clave: orfebrería, oro, fenicios, necrópolis, Malaca
Abstract: We study the golden objects from the Phoenician burials from Malaga. The most of them can be dated at VI century b. C. At the same time we value the possible existence in this site of a workshop that, with his logical parallelism with another Phoenicians pieces from central and western Mediterranean, it seem. To show some formals and decorative details.

Key words: goldsmith, gold, Phoenicians, necropoli, Malaca

\section{INTRODUCCIÓN}

No cabe duda de que durante siglos uno de los aspectos más oscuros y problemáticos de la antigua colonia fenicia de Malaca ha sido la localización y estudio de sus sepulturas. De hecho, hasta hace muy poco apenas contábamos con vagas noticias sobre algún enterramiento aislado en la calle Andrés Pérez o alguna necrópolis que al ofrecer varias tumbas de época romana había sido adscrita a dicho período, como es el sector de calle Campos Elíseos en la ladera de la colina de Gibralfaro. Tan sólo a partir de las últimas décadas las excavaciones emprendidas en varios solares de la capital malagueña han permitido llenar este vacío, ya sea aportando nuevos hallazgos en las calles Mundo Nuevo, Beatas y Zamorano, o mediante la reexcavación de la zona de Gibralfaro.

\footnotetext{
* Museo de Pizarra. Grupo de Investigación "El legado de la Antigüedad" (HUM-741) de la Universida de Almería.
}

Por ello nos parece interesante dar a conocer parte de estos nuevos descubrimientos, en este caso la orfebrería descubierta en dichos enterramientos, ya que el número de ejemplares áureos conocidos se ha visto notablemente incrementado en los últimos años, con la particularidad de que la mayor parte de las piezas descubiertas pertenecen a una cronología, como es el siglo VI a. C., hasta el momento no bien definida en los contextos semitas peninsulares, tal y como sucede, por ejemplo, con el caso del taller gaditano, sin duda el mejor analizado de todo el occidente peninsular (Perea 1989: 60; 2000: 284).

Lamentablemente por ahora carecemos de estudios analíticos que permitan discernir aspectos imposibles de evidenciar de otra forma, y cuya realización en el futuro sería de desear, como se ha hecho, por ejemplo, en lo concerniente a las producciones gaditanas (Perea 1991: 1133-1140), a pesar de lo cual no cabe duda de que estos hallazgos pueden ofrecer nueva información que permitirá avanzar en el estudio de la joyería fenicia no sólo de esta localidad andaluza, sino de todo el sur peninsular. 


\section{LOS CONTEXTOS ARQUEOLÓGICOS.}

Las primeras joyas halladas en Málaga nos remontan al año 1875 (Rodríguez de Berlanga 1891: 329-330; 1999: 36-37), fecha en la que aparecieron varios enterramientos de incineración dentro de una cista de sillares de los que nos han llegado escuetas noticias y cuya datación todavía hoy sigue presentando problemas. Así, si en un primer momento se dató entre los siglos V-IV a. C. (Gran-Aymerich 1986: 131-132), más tarde se rebajó dicha cronología hasta fechas cercanas al cambio de Era (Rodríguez Oliva 1993-94: 229-233). En su interior, junto con otros restos, se encontró una caja de plomo en la que se habían depositado algunas bisagras de hueso y tres discos de oro de distintos tamaños con forma de rosetón, el mayor con 32 pétalos estilizados y los dos menores con 16 (Rodríguez de Berlanga 1891: 330; 1999: 36-37, 160).

Otro hallazgo efectuado ese mismo siglo XIX o comienzos del siguiente nos remite a la necrópolis situada en la colina de Gibralfaro, de la que se conocen más de una veintena de tumbas de distintas fechas, como son los siglos VI, II-I a. C. y I d. C. (Martín y Pérez-Malumbres 1999: 15-31), y que habría facilitado en otro de los sectores no documentados una figurita del dios Bes en oro de la que ningún otro dato nos ha llegado (Rodríguez de Berlanga 1999: 40).

En un nuevo sector de esta misma necrópolis, en concreto en el hipogeo de Mundo Nuevo, fechable en el siglo VI a. C., se documentaron cinco pendientes que en su origen debieron alcanzar la media docena. Dicha cámara albergaba dos fosas con tres inhumaciones adscribibles a esa cronología, así como restos de otro individuo de fecha más reciente, hacia el 400 a. C. que se localizó fuera de las mismas (Martín et alii 2003: 147-148).

Más recientemente se ha comprobado la existencia de varios enterramientos de incineración de calle Zamorano, también datados en el siglo VI a. C., en los que se han documentado distintos elementos, varios de ellos áureos, pertenecientes cuando menos a dos collares. El primer hallazgo tuvo lugar el año 2003, cuando dentro de un hoyo de tendencia circular aparecieron una pareja de pendientes-arete de oro, siete cuentas esféricas gallonadas y cuatro cuentas fusiformes del mismo material, sin olvidar otras dos cilíndricas y dos esféricas confeccionadas en piedra (Cumpián 2003; AAVV 2005: 78).

El segundo se produjo en 2004, cuando se excavó una fosa en cuyo fondo de adobe se había procedido a efectuar la cremación del cadáver. De aquí se han recuperado un amuleto en forma de ojo de Horus, un colgante-medallón de oro, 18 cuentas esféricas gallonadas, también de oro, y otras 31 esféricas hechas con idéntico metal, sin que olvidemos 29 cuentas de pasta vítrea, algunas de ellas soldadas entre sí (Melero 2004).

\section{LAS JOYAS}

Hasta el momento las tumbas documentadas en la Malaca fenicia han facilitado un total de 68 piezas de oro que podemos agrupar en amuletos, cuentas de collar, discos, colgantes-medallones y pendientes, sin que contabilicemos el que debía formar pareja con uno de los procedentes de Mundo Nuevo, ni los pequeños fragmentos de una posible cuenta del segundo collar de calle Zamorano. Todo ello queda reflejado en el siguiente gráfico:

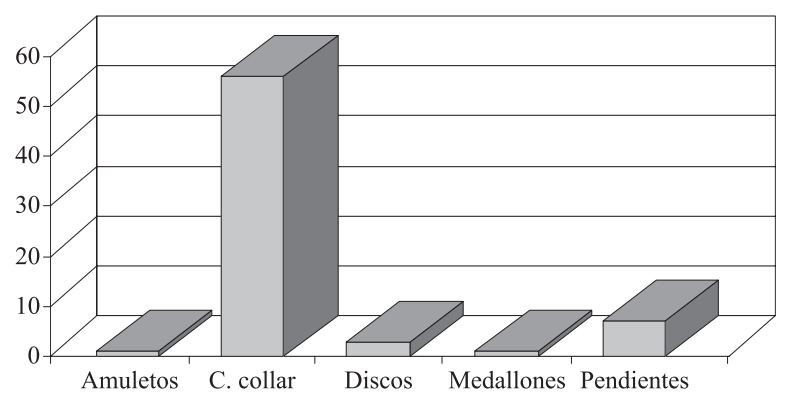

Como ya indicamos, nada sabemos sobre el primero de estos grupos que incluye un único ejemplar como es el amuleto localizado en Gibralfaro que representaba al dios Bes, si bien cabe dentro de lo posible que se tratase de un colgante-amuleto como el Path-pateco o los mismos Bes localizados en Cádiz (Perea 1986: 300; 1989: 63).

El segundo es, con diferencia, el más numeroso. En efecto, los dos collares documentados en las tumbas de calle Zamorano ofrecen 56 cuentas pertenecientes a distintos tipos. El collar más completo dispone de 49 cuentas, de las que 15 -número de inventario 13385/2- se inscriben en el grupo VAb de A. Perea (1986: 299 y 311), grupo IIG de B. Quillard (1979: 110), con 5 mm. de diámetro y un peso de 0,10 gr. ofreciendo una decoración gallonada con un pequeño resalte en ambos extremos (lám.1). Cuentas con estas características son bien conocidas en producciones localizadas en la necrópolis de Villaricos (Astruc 1951: XV), así como en piezas gaditanas del siglo IV a. C., fecha también sugerida para las localizadas en Cartago (Quillard 1979: 116).

En cuanto a las 34 restantes $-n^{\circ}$. inv. 13385/3-, con un diámetro de $3,5 \mathrm{~mm}$. y un peso de 0,04 gr., hemos de indicar que son más pequeñas de tamaño, con forma ovalada y todas ellas lisas y carentes de remate, pudiendo adscribirse al grupo Ib que la citada autora establece para 


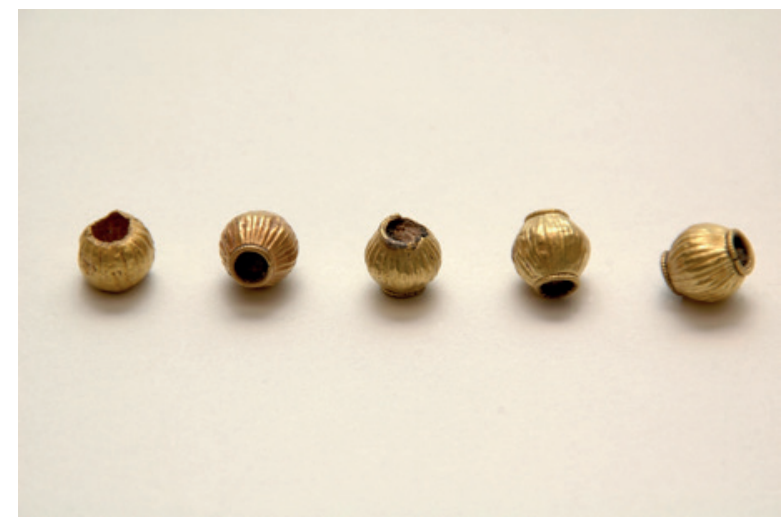

Lámina1. Cuentas de collar de calle Zamorano, Museo de Málaga (Fuente: L. Hidalgo).

los hallazgos cartagineses (Quillard 1979: 110), presentes también en tumbas de Villaricos (Astruc 1951: lám.XV).

Así mismo, de las siete cuentas recuperadas del segundo collar, seis pertenecen igualmente al tipo VAb de Perea, IIG de Quillard, en tanto el mal estado de conservación de la otra impide cualquier apreciación al respecto.

Hasta el presente contamos con un único medallón-colgante procedente de calle Zamorano $-\mathrm{n}^{\mathrm{o}}$. inv. $13385 / 1-$. Se trata de una lámina de oro discoidal de 1,8 gr. de peso y $19 \mathrm{~mm}$. de diámetro, el cual muestra una forma de corazón invertido y ónfalos central, así como un sistema de suspensión en forma de carrete (láms. 2-3). Esta clase de discos está bien constatada en las necrópolis de Jardín (Schubart y Maass-Lindemann 1995: 147), Cádiz (Perdigones et alii 1990: 25-27) y, ya fuera de la Península Ibérica, en Tharros (Acquaro 1985: 8; Pisano 1997: 441) y Cartago, lugar este último donde estas piezas se inscriben en el tipo 8 de B. Quillard (1979: 81-88; Pisano 1997: 424).

Los medallones de Andrés Pérez (lám. 4) estaban formados por una lámina en forma de rosetas que, en el caso del disco de mayores dimensiones tenía 32 pétalos, siendo descrito con unas dimensiones de $65 \mathrm{~mm}$. de diámetro y 8 gr. de peso, y en los otros dos 16, con $34 \mathrm{~mm}$. de diámetro y un peso de 1 y 0,8 gr. respectivamente, portando todos ellos un granate en su centro. Aunque estas rosetas no son en absoluto desconocidas para los orfebres fenicios, suelen presentar un número distinto de pétalos que varía entre doce y ocho, como vemos en joyas de Cádiz (Perea 1989: 63), Tharros (Acquaro 1985: 10; Pisano 1997: 441) o Cartago (Quillard 1979: 93-95). Sobre su funcionalidad Rodríguez de Berlanga (1891: 329; 1999: 36-37; Sánchez 1974: 77-78) supuso que podían formar parte de una vestimenta, si bien la aparición en tumbas del siglo VI a. C. de la necrópolis chipriota de Salamina (Karageorghis 1971: 136) de varios medallones similares a los de Andrés Pérez formando parte de la decoración de un mueble allí depositado, hace que no quepa descartar un uso similar para los ejemplares malagueños, máxime si recordamos que éstos aparecieron acompañados de cilindros de hueso que no son sino bisagras de un cofre o caja.

Todos los pendientes de Mundo Nuevo, que podemos incluir en el grupo III.3.C de M. J. Almagro (1986: 34)

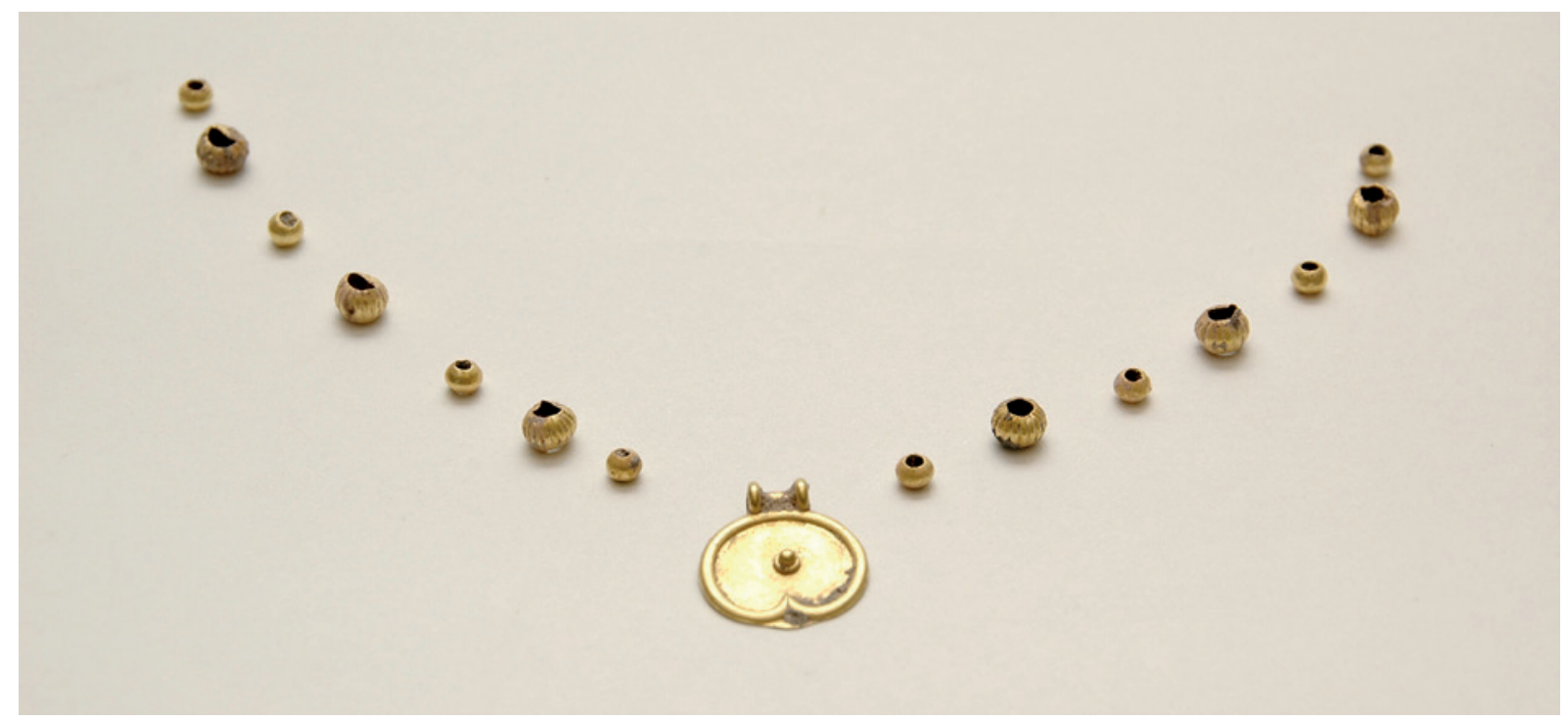

Lámina 2. Colgante-medallón de calle Zamorano, Museo de Málaga (Fuente: L. Hidalgo) 


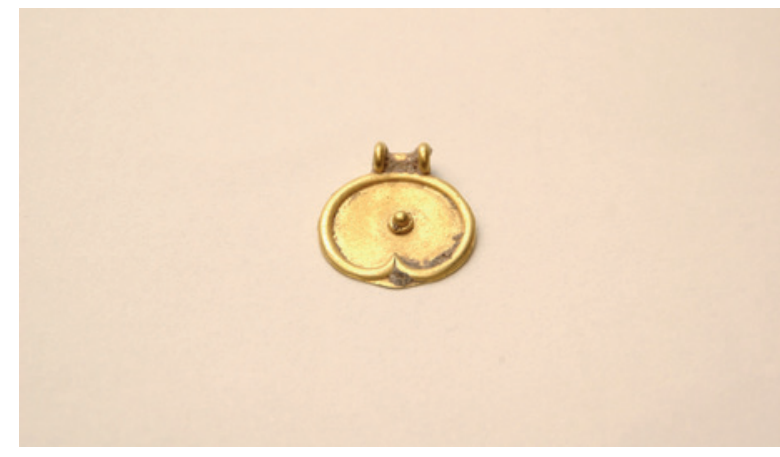

Lámina 3. Cuentas y colgante-medallón de uno de los collares de calle Zamorano, Museo de Málaga (Fuente: L. Hidalgo).

y pueden datarse en el siglo VI a. C., conforman tres parejas aun cuando una de ellas está incompleta. A pesar de su similitud, pues en todos los casos se trata de pendientes fusiformes dobles, no dejan de mostrar ciertas diferencias interesantes. Así, el pendiente único $-\mathrm{n}^{\mathrm{o}}$. inv. 13.253- (lám. 5), tiene unas dimensiones de $35 \times 30 \mathrm{~mm}$., y está formado a partir de una sola lámina hueca de tendencia fusiforme con un pequeño cierre de bronce que termina en dos pequeñas barritas que entran en sendas arandelas de oro (Martín et alii 2003: 147). Otras dos arandelas situadas en los extremos superiores denotan que este pendiente debía portar elementos de suspensión que no se han conservado, similares muy posiblemente a otras piezas conocidas en puntos como

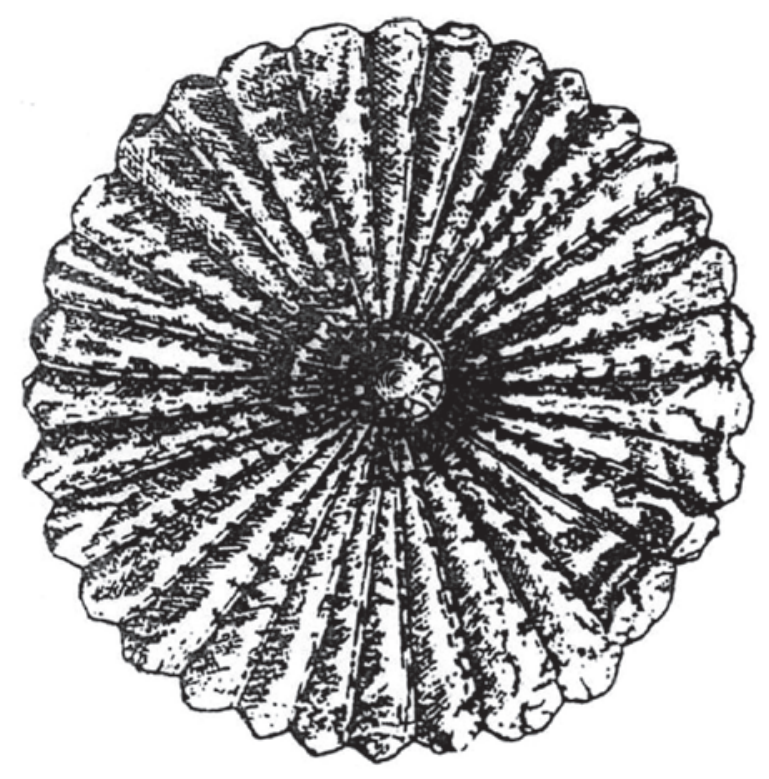

Lámina 4. Medallón de calle Andrés Pérez (Fuente: M. Rodríguez de Berlanga).

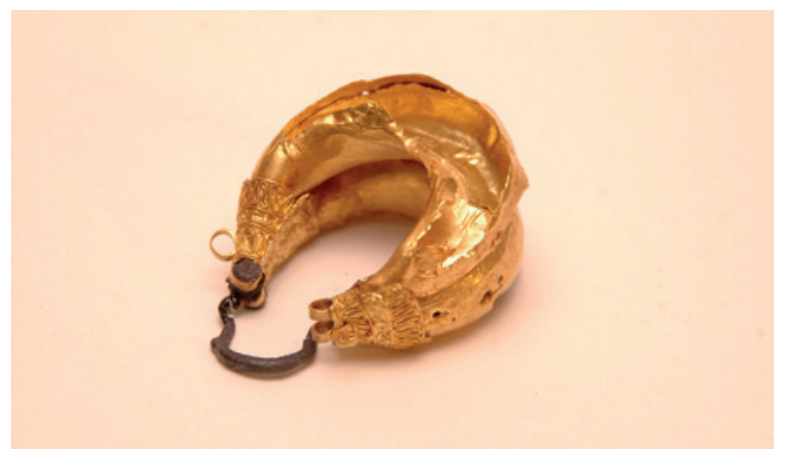

Lámina 5. Pendiente fusiforme doble de Mundo Nuevo, Museo de Málaga (Fuente: L. Hidalgo).

Tharros (Pisano 1997: 427 y 431), ofreciendo un gran parecido a los que muestran las arracadas fusiformes simples de Marchena, aunque parece que su lugar de procedencia no es otro que el yacimiento de Montemolín (Bandera 1989: 52-55 y 115-117). En cuanto a su decoración, cabe decir que se realiza mediante una doble fila de meandros acompañada de otra de puntos, éstos últimos hechos a buril desde el reverso de la lámina.

Otros dos $-n^{\circ}$. inv. 13.264 y 13.265 - miden 25 x 25 x $14 \mathrm{~mm}$. y 24 x 25 x $14 \mathrm{~mm}$., respectivamente, aun cuando su peso es idéntico: 5,9 gr. (lám. 6); muestran una lámina que se adosa a su parte externa decorada con tres bandas de puntos paralelas delimitadas por hilos y decoración de puntos, puntos que fueron hechos desde su reverso con la técnica del repujado. En ambos casos los pendientes se cierran mediante pequeñas laminitas que rematan en hilos de oro enrollados con dos arandelas que albergarían el sistema de suspensión perdido en estas piezas (Martín et alii 2003: 147).

Finalmente, la última pareja $-\mathrm{n}^{\mathrm{o}}$. inv. $13.262 \mathrm{y}$ 13.263- tiene unas dimensiones de $27 \times 20$ x $13 \mathrm{~mm}$. y $26 \times 20 \times 13 \mathrm{~mm}$., con un peso de 4,2 gr. (lám. 7), siendo como los anteriores también gemela entre sí, con remates que de nuevo se hacen mediante varios hilos enrollados, a la vez que cuenta con un cierre de bronce (Martín et alii 2003: 147-148; Pérez-Malumbres et alii 2003: 788). En contextos fenicios peninsulares sólo conocemos piezas semejantes a esta última pareja en tumbas del grupo J de la necrópolis de Villaricos (Astruc 1951: lám.: XLI; Almagro 1986: 108), aun cuando son varios los enclaves indígenas que han facilitado piezas de estas características como pueden ser el extremeño palacio-santuario de Cancho Roano o la necrópolis ibérica de La Bobadilla en Jaén, con unas cronologías que oscilan entre los siglos VI-V a. C. (Perea 2003: 201 y 213).

Por lo que respecta a los dos localizados en Zamorano (lám. 8) podemos indicar que se adscriben al grupo 


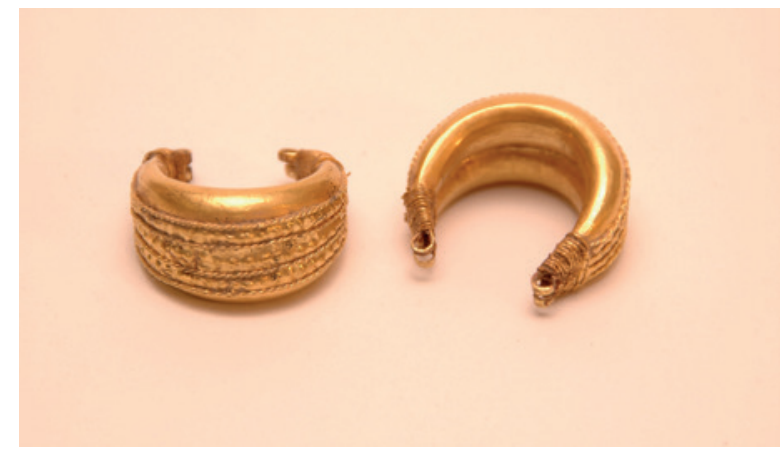

Lámina 6. Pareja de pendientes fusiformes dobles de Mundo Nuevo, Museo de Málaga (Fuente: L. Hidalgo).

IVAa de Perea (1986: 298 y 311), es decir, pendientes cerrados simples, lo que no excluye que también pudieran haber sido empleados como nezem o adornos nasales según ponen de manifiesto las terracotas ibicencas (Perea 1985: 39; 1986: 63). Su confección se realiza a partir de un hilo de oro que es cerrado en su extremo enrollándose sobre sí mismo, pudiendo citarse piezas similares en tumbas de Cádiz (Perea 1986: 298-299), Villaricos (Astruc 1951: láms. XV, XX, XLI) y Puig des Molins (Fernández 1992: 185-187).

\section{LA ORFEBRERÍA FENICIA EN MALACA}

Antes de examinar los datos que pueden facilitarnos estos objetos cabría recordar que a las piezas ya comentadas podemos sumar otros dos ejemplares también de oro procedentes de Malaca. El primero es un colgantemedallón carente de un contexto arqueológico preciso descubierto el siglo pasado y que ha sido datado a finales del siglo VII a. C. (láms. 9-10). Esta pieza ingresó en el Museo Arqueológico Nacional en 1923 formando parte de la colección Vives $-\mathrm{n}^{\mathrm{o}}$ inv. 1923/60/1017-(Vives 1917: 18) ${ }^{1}$, si bien para algunos autores era considerada como una joya perdida (Marín 1996: 536). Se trata de una pieza circular de $18 \mathrm{~mm}$. de diámetro con suspensión en forma de carrete. Compuesto por dos láminas unidas por un aro, su decoración, de carácter claramente egiptizante, pero que para algunos investigadores no oculta que puede tratarse de una obra hecha en talleres sirios (Blanco 1956: 47-48), muestra en una de sus caras un faraón armado de maza que sujeta a un enemigo vencido, junto a una figura que representa al

1. Agradecemos a $D^{\mathrm{a}}$ Magdalena Barril Vicente, conservadora del Museo Arqueológico Nacional, la ayuda prestada para la localización de esta pieza.

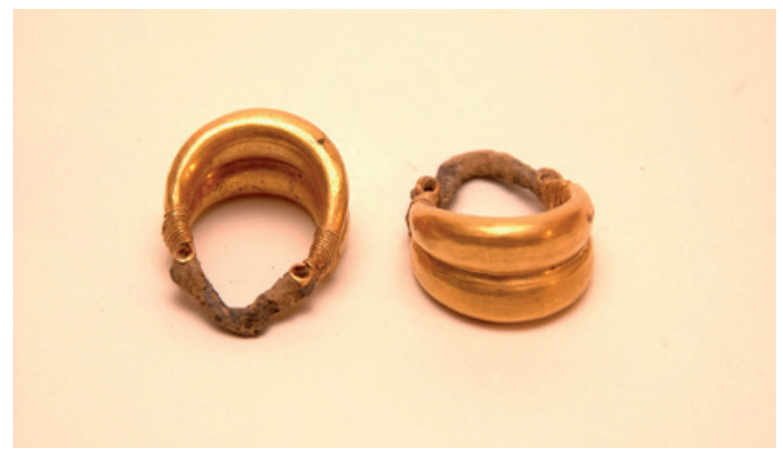

Lámina7. Pareja de pendientes fusiformes dobles de Mundo Nuevo, Museo de Málaga (Fuente: L. Hidalgo).

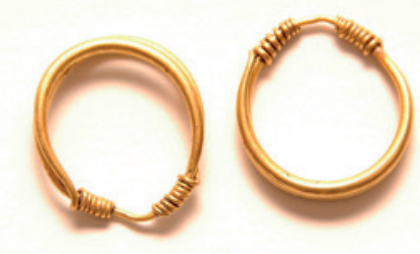

Lámina 8. Pareja de pendientes de calle Zamorano, Museo de Málaga (Fuente: L. Hidalgo)

escudero portasandalias, mientras que en la otra cara del medallón vemos el árbol sagrado entre dos cabras rampantes que trepan por él (Sánchez 1974: 77; Blázquez 1975: 144-146).

En cuanto a la segunda pieza que podemos comentar corresponde a un pendiente cerrado tipo nezem proveniente de la zona urbana exhumada en calle Císter, el cual ha sido datado en el siglo $\mathrm{V}$ a. C. por sus excavadores (Martín 2007: 31).

Las técnicas empleadas para la elaboración de estas joyas contemplan la laminar, la más antigua conocida por el ser humano, según comprobamos en los pendientes huecos de Mundo Nuevo, el repujado con cincel, como se advierte en los discos de Andrés Pérez (Rodríguez 1891: 329; 1999: 37) y el medallón egiptizante que acabamos de comentar (Sánchez 1974: 77), o algunos pendientes fusiformes dobles (Martín et alii 2003: 147; Pérez-Malumbres et alii 2003: 787-788). Así mismo, se comprueba también la existencia de filigrana, técnica de claro origen oriental, en la que, mediante distintas variantes (Bandera 1986: 527-528), se aplican finos hilos sobre un fondo. Otra técnica que podemos 


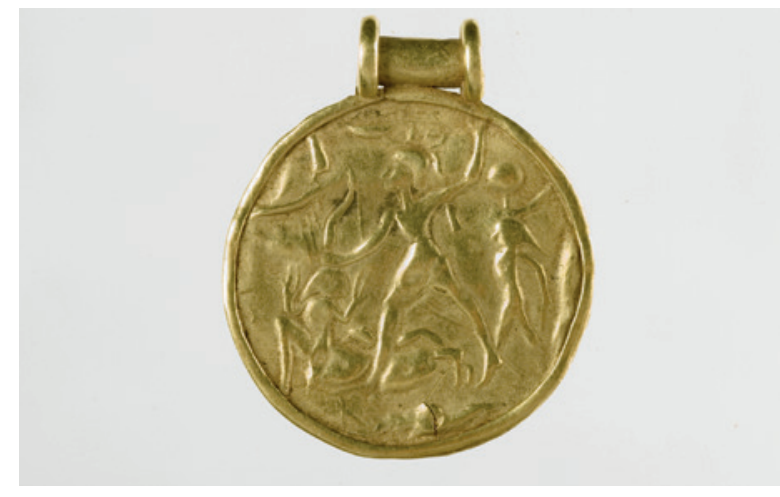

Lámina 9. Anverso del medallón de la colección Vives, Museo Arqueológico Nacional (Fuente: Museo Arqueológico Nacional)

documentar es la del granulado, también con un origen en el Mediterráneo oriental y en la que pequeños gránulos de oro son soldados a una lámina (Bandera 1986: 529-530), como puede apreciarse en el ónfalos del colgante en forma de corazón de calle Zamorano.

Cabe plantear el uso de soldaduras, por ejemplo, en la unión de las dos láminas que conforman el colgantemedallón, así como para las laminitas decoradas que se adosan a algunos pendientes de Mundo Nuevo. En realidad, tanto la filigrana como el granulado requieren de soldadura, que en el caso del taller gaditano sabemos, gracias a los microanálisis realizados, que se trata de una aleación terciaria en la que se empleó oro, plata y cobre (Perea 1992: 79). Lamentablemente, la inexistencia de este tipo de análisis nos impide valorar si en el caso malacitano se utilizó la misma aleación o no, si bien no cabe duda de que el soldante usado debió tener un punto de fusión más bajo que el de la pieza, los $1063^{\circ} \mathrm{C}$ necesarios para el fundido del oro (Bandera 1986: 521-522).

Por otro lado, debemos reseñar la existencia de piedras semipreciosas que se engarzan, en este caso los granates que muestran los discos de Andrés Pérez (Rodríguez de Berlanga 1891: 329; 1999: 37), algo poco habitual en contextos arqueológicos peninsulares (Bandera 1986: 535), pero que podemos observar en algunas joyas procedentes de Sidón que se fechan entre los siglos V y IV a. C., donde se emplean ágatas y turquesas (Parrot et alii 1975: 108).

Los motivos decorativos son más bien limitados, como por otra parte suele ser habitual en la orfebrería fenicia. Éstos se limitan a rosetas, aunque con un número distinto de pétalos y sin que se emplee la técnica del esmaltado como acontece en colgantes, arracadas y pendientes procedentes de Cádiz (Bandera 1979-80: 34; 1985: 41-42; Perea 1986: 305) y Tharros (Acquaro 1985: 10). Además, cabe mencionar el gallonado de

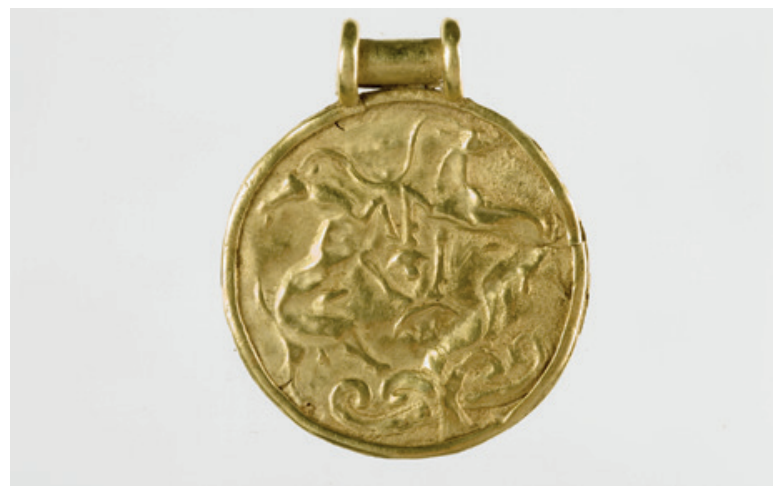

Lámina10. Reverso del medallón anterior, Museo Arqueológico Nacional (Fuente: Museo Arqueológico Nacional).

algunas de las cuentas de collar, las líneas de puntos y los meandros que conforman adornos de corte geométricos, sin que olvidemos alguna escena egiptizante. Incluso cabría añadir a este apartado los hilos enrollados que rematan los extremos de los pendientes, como sucede de nuevo en Cádiz (Perea 1989: 63), siendo de reseñar cierta originalidad en lo concerniente a las láminas que se adosan a los pendientes fusiformes.

El sistema habitual de suspensión para los medallones es el carrete cilíndrico, muy habitual en las joyas de Cádiz de cierta entidad y que tiende a perder importancia a partir del siglo VI a. C. (Perea 1986: 301; 1989: 61), al igual que sucede en Cartago (Quillard 1979: 6970). Para los pendientes, en cambio, se utilizó un material distinto al oro, como es el bronce.

Desde un punto de vista cronológico la gran mayoría de estas piezas se insertan en una etapa antigua, que podíamos situar en el siglo VI a. C., existiendo inclusive algún ejemplo de finales de la centuria anterior, a tenor de la datación sugerida para el medallón egiptizante (Sánchez 1974: 77), siendo, en cambio, muy pocas las piezas datables en el siglo $\mathrm{V}$ a. $\mathrm{C}$., al igual que en las fechas cercanas al cambio de Era, siempre que situemos en este momento la tumba de Andrés Pérez. Todo ello sin que olvidemos la posible existencia de un período de amortización más o menos prolongado para estas piezas de oro, algo por otra parte difícil de valorar en nuestro caso (Peserico 1997: 418).

Por otro lado, cabe indicar que las distintas características que presentan las diferentes parejas de pendientes fusiformes, así como el hecho de que cada pareja tenga el mismo tamaño y casi idéntico peso, parece coincidir con lo expuesto por A. Perea (2000: 284) para la fase más antigua del taller de Cádiz en la que, salvo las cuentas de collar que por su simpleza fueron elaboradas en serie, no sucede lo mismo con el resto de piezas que son 
trabajadas de forma más individualizada. Por su parte G. Pisano (1995: 522-523) apunta que durante la etapa a la que podemos asignar la mayor parte de estas piezas, el ya comentado siglo VI a. C., los talleres fenicios habrían puesto en marcha un proceso en el que, racionalizando las técnicas empleadas, lograron una mayor estandarización en la fabricación de estas piezas como respuesta a un aumento de la demanda de objetos hechos en oro, según vemos en puntos como la mencionada Gadir o Tharros.

Por otro lado, uno de los elementos que porta uno de los collares de calle Zamorano es de origen egipcio, en concreto un ojo de Horus calado hecho en marfil o hueso pues es difícil definirse en uno u otro sentido, el cual presenta sendas perforaciones laterales para ser ensartado. No cabe duda de que éste fue uno de los amuletos más populares en todo el Mediterráneo durante la Antigüedad, por lo que sólo recordaremos su aparición en contextos fenicios ibicencos (Fernández y Padró 1986: 42-48) y gaditanos (Perdigones et alii 1990: 74 75). Ello nos lleva a recordar el carácter mágico protector que cabe atribuir a estos collares, ya llegasen a su poseedor como regalo o como mercadería, en función del cual la protección del objeto se hace extensiva a quien lo porta, por lo que su uso contempla facetas bastante más amplias que el simple adorno o signo de estatus social (Ruano 1996: 79-81), siendo así que a estos dos collares cabe sumar otro más, esta vez sin aditamentos áureos, localizado en una tumba de incineración de calle Beatas datada en el siglo I a. C, y que estaba integrado por amuletos -higas- cuentas de pasta vítrea y algunas monedas de la ceca de Malaca ensartadas (Mora 2001: 127-128).

\section{CONCLUSIONES}

Aunque el número de piezas de oro procedentes de Malaca no alcanza todavía el volumen que en la Península Ibérica ofrece Gadir con más de dos centenares de piezas (Perea 1992: 81), no es menos cierto que éste se ha incrementado de manera notable en los últimos años, pues hasta el momento se dispone de 68 ejemplares, a los que debemos sumar los dos no cuantificados al estudiar estos hallazgos funerarios (pendiente y cuenta de collar), además del colgante-medallón y el otro pendiente proveniente de una zona de hábitat, lo que nos da un total de 72 joyas.

Aunque aún no estamos en condiciones de afirmar sin ninguna duda que en Malaca existió un taller de orfebrería en época fenicia, no es menos cierto que estos hallazgos aportan nuevos datos para abrir este interesante debate, pues a pesar de sus innegables concomitancias con la joyería de puntos como Gadir, Tharros o Cartago, en estos hallazgos comienzan a vislumbrarse aspectos que parecen documentarse sólo en estos ejemplares malacitanos.

En todo caso quizás sea conveniente comenzar a plantearnos si Cádiz fue el único taller de orfebrería que existió en lo que últimamente se ha dado en llamar Unidad de Producción de Estilo Colonial (Blanco y Celestino 1998: 78), o bien pudieron haber existido otros centros más o menos autónomos, cuestión esta última que nos parece más plausible.

Finalmente, hemos de indicar que el $95 \%$ de estas piezas se datan en una etapa arcaica, como son los siglos VII-VI a. C., y en especial en esta última centuria, período en el que supera incluso en número de hallazgos a la propia Gadir, aunque tal vez este hecho se vea algo mediatizado por el alto número de cuentas de collar. Sea como fuere, las piezas conocidas, en particular los pendientes fusiformes dobles, parecen inscribirse en la tónica señalada por algunas autoras sobre la existencia en esta centuria de una producción fabricada en serie para abastecer una mayor demanda.

Paradójicamente hasta el presente no conocemos ejemplares que pudiéramos situar en el siglo IV a. C., fecha de apogeo del taller de gaditano, por lo que no es posible establecer comparaciones entre ambos yacimientos que habrán de formularse en un futuro esperemos que no muy lejano.

\section{BIBLIOGRAFÍA}

AAVV (2005): "Actividades arqueológicas en Andalucía”, Anuario Arqueológico de Andalucía 2003, I: 78. Sevilla.

ACQUARO, E. (1985): "Las joyas de Tharros (Cerdeña)", Revista de Arqueología 48: 6-11.

ALMAGRO GORBEA, M. J. (1986): Orfebrería feniciopúnica del Museo Arqueológico Nacional, Madrid.

ASTRUC, M. (1951): La necrópolis de Villaricos, Madrid.

BANDERA ROMERO, M. L. (1979-80): “Orfebrería gaditana: técnicas y tipología”, Boletín del Museo de Cádiz II: 33-41.

- (1986): "Introducción al estudio de la joyería prerromana peninsular: técnicas", Habis 17: 515-538.

- (1989): La joyería prerromana en la provincia de Sevilla, Sevilla.

BLANCO FERNÁNDEZ, J. L. y CELESTINO PÉREZ, S. (1998): "La joyería Orientalizante peninsular. Diversidad y particularidades a la luz de los últimos descubrimientos", Complutum 9: 61-83.

BLANCO FREIJEIRO, A. (1956): “Orientalia. Estudio de objetos fenicios y orientalizantes en la Península Ibérica", Archivo Español de Arqueología 39: 3-51. 
BLÁZQUEZ MARTÍNEZ, J. M. (1975): Tartessos y los orígenes de la colonización fenicia en Occidente, $2^{\mathrm{a}}$ ed., Salamanca.

CUMPIÁN RODRÍGUEZ, A. (2003): Excavación arqueológica de urgencia en el solar sito en calle $\mathrm{Za}$ morano $n^{\circ}$ 3-9 y calle Tiro $n^{\circ}$ 9-11 (Barrio de la Trinidad-Málaga). Informe preliminar, informe depositado en la Delegación Provincial de la Junta de Andalucía en Málaga, Málaga.

FERNÁNDEZ, J. H. (1992): Excavaciones en la necrópolis de Puig des Molins (Eivissa). Las campañas de D. Carlos Román Ferrer: 1921-1929, Ibiza, 3 vols.

FERNÁNDEZ, J. H. y PADRÓ, J. (1986): Amuletos de tipo egipcio del Museo Arqueológico de Ibiza, Ibiza.

GRAN-AYMERICH, J. M. J. (1986): “Málaga fenicia y púnica”, Los fenicios en la Península Ibérica, I: 127-148. Sabadell.

KARAGEORGHIS, V. (1971): Chipre. Barcelona.

MARÍN CEBALLOS, M. C. (1996): "La religión fenicio-púnica en España (1980-1993)”, Hispania Antiqua 18: 533-568.

MARTÍN RUIZ, J. A. (2007): "La cultura material fenicia malacitana: restos de un pasado milenario", Los orígenes de la ciudad. Málaga fenicia: 21-46. Málaga.

MARTÍN RUIZ, J. A. y PÉREZ-MALUMBRES LANDA, A. (1999): Malaca fenicia y romana: la necrópolis de Campos Elíseos. Catálogo de la exposición, Málaga.

MARTÍN RUIZ, J. A.; PÉREZ-MALUMBRES LANDA, A. y GARCÍA CARRETERO, J. R. (2003): "Tumba de cámara de la necrópolis fenicia de Gibralfaro (Málaga, España)", Rivista di Studi Fenici XXXI, 2: 139-160.

MELERO, F. (2004): Informe preliminar Intervención Arqueológica Preventiva en los solares $n^{\circ}$ 9-11 de calle Tiro. Esquina Zamorano (Málaga, barrio de la Trinidad), informe depositado en la Delegación Provincial de la Junta de Andalucía en Málaga, Málaga.

MORA SERRANO, B. (2001): "La moneda en la ciudad de Malaca (siglos III a. C.-VI d. C.)", en $\mathrm{Mo}$ neda $i$ vida urbana. $V$ Curs d'Història monetària d'Hispania: 123-143. Barcelona.

PARROT, A.; CHEHAB, M. H. y MOSCATI, S. (1975): Los fenicios. La expansión fenicia. Cartago. Bilbao.
PERDIGONES MORENO, L.; MUÑOZ VICENTE, A. y PISANO, G. (1990): La necrópolis fenicio-púnica de Cádiz. Siglos VI-IV a. C., Roma.

PEREA CAVEDA, A. (1985): "Piezas singulares de orfebrería gaditana en el M.A.N.”, Boletín del Museo Arqueológico Nacional, III: 37-42.

- (1986): "La orfebrería púnica de Cádiz", en Los fenicios en la Península Ibérica, I: 295-322. Sabadell.

- (1989): "Cádiz: orfebrería fenicia”, en El oro en la España prerromana: 58-67. Madrid.

- (1991): "Metodología y técnicas actuales para el estudio de la orfebrería antigua: el taller de Cádiz", en Atti del II Congresso Internazionale di Studi Fenici e Punici, III: 1133-1142. Roma.

- (1992): "El taller de orfebrería de Cádiz y sus relaciones con otros centros coloniales e indígenas", en Producciones artesanales fenicio-púnicas. VI Jornadas de Arqueología fenicio-púnica: 75-86. Ibiza.

- (2000): "Comportamientos de mercado en la producción orfebre del taller de Cádiz", en Intercambio y Comercio Preclásico en el Mediterráneo: 281292. Madrid.

- (2003): “Cancho Roano: estudio tecnológico de los objetos de oro", en Cancho Roano VIII. Los materiales arqueológicos, I: 195-228. Madrid.

PISANO, G. (1995): "Riflessioni sull'oreficeria", en I fenici: ieri, oggi, domini: 519-524. Roma.

— (1997): "I gioielli", I fenici. 418-444. Milano.

QUILLARD, B. (1979): Bijoux carthaginois. I. Les colliers. Louvain.

RODRÍGUEZ DE BERLANGA, M. (1891): El nuevo bronce de Itálica. Málaga.

- (1999): Catálogo del Museo Loringiano (Primera edición: Málaga, 1903). Málaga.

RODRÍGUEZ OLIVA, P. (1993-94): "Sobre algunos tipos de urnas cinerarias de la provincia Baetica y notas a propósito de la necrópolis de la calle Andrés Pérez de Málaga”, Mainake XV-XVI: 223-242.

RUANO RUIZ, E. (1996): Las cuentas de vidrio prerromanas del Museo Arqueológico de Ibiza y Formentera. Ibiza.

SÁNCHEZ LAFUENTE, J. (1974): “Orfebrería antigua de Málaga”, Jábega 8: 73-80.

SCHUBART, H. y MAASS-LINDEMANN, G. (1995): "La necrópolis de Jardín", Cuadernos de Arqueología Mediterránea I: 57-213.

VIVES Y ESCUDERO, J. (1917): Estudio de arqueología cartaginesa. La necrópolis de Ibiza. Madrid. 